\title{
ATRIBUTOS DA METRÓPOLE MODERNA
}

Regina Maria Prosperi Meyer

Arquiteta e Urbanista, Professora da Faculdade de Arquitetura e Urbanismo da Universidade de São Paulo

\begin{abstract}
Resumo: Este artigo busca situar a atual transição metropolitana - da metrópole moderna à metrópole contemporânea - no quadro geral da reestruturação tecnológica do modo de produção. A organização material da metrópole é entendida como uma expressão do modo de produção e não como seu reflexo. Procura mostrar como essa premissa de trabalho garante à metrópole contemporânea um protagonismo no desenvolvimento da sociedade informacional e que para exercê-lo são desenvolvidos atributos espaciais e territoriais específicos. A descrição desses atributos e da sua organização territorial e espacial conduz à postulação de que as grandes infra-estruturas urbanas representam hoje a possibilidade de enfrentar duas características do processo de transição: a fragmentação territorial e a dispersão funcional.

Palavras-chave: desenvolvimento metropolitano; metrópole contemporânea; economia e urbanização.
\end{abstract}

A $\mathrm{s}$ reflexões críticas sobre o desenvolvimento material do capitalismo industrial, produzidas no século XIX, utilizaram largamente as questões urbanas e principalmente metropolitanas para evidenciar teses e sustentar argumentos. As condições de vida nas grandes metrópoles, sobretudo a pobreza urbana e o "malestar" diante dos novos atributos espaciais da metrópole foram dissecados por seminais análises sociopolíticas e artísticas. A intenção de criar um modelo de análise capaz de contrapor, de maneira eficiente, o modo de produção capitalista ao modo de produção socialista forneceu a esses estudos e depoimentos uma enorme força e relevância. No auge do processo de industrialização inglês, em torno das décadas de 1840 e 1850, Friedrich Engels (1820/ 1895) descreve a degradada condição dos setores urbanos ocupados pelos operários de Londres e Manchester, enquanto Charles Baudelaire (1821/1867) buscava, pelo discurso lírico revelar o sofrimento do homem moderno obrigado a conviver com o descompasso que se instalou entre o progresso material e a vida espiritual em Paris, quando as obras de Napoleão III executadas pelo Barão de Haussmann se concretizaram. Ambos abriram caminho para a observação e interpretação da experiência metropolitana, criando uma tradição de enorme abrangência que ainda hoje se revela eficaz e vigorosa. ${ }^{1}$

A partir de uma abordagem historicista e culturalista e, em muitos aspectos, também alimentada por fórmulas lançadas no século XIX, o historiador americano Lewis Munford, em seu clássico livro $A$ cidade na história ${ }^{2}$ analisa a metrópole moderna preconizando o desastre que representava para as metrópoles as intervenções de caráter modernista que não levavam em consideração a continuidade cultural das cidades. Seu estudo, essencialmente denunciador, é uma reflexão de grande força antecipatória sobre o papel corrosivo que a tecnologia assumida de forma arbitrária exerce sobre as cidades. Ao percorrer os formidáveis aspectos negativos da civilização metropolitana, Munford sintetizou os complexos problemas já esboçados nos séculos XVIII e XIX e que alcançaram o século XX desafiando a capacidade de análise e de gestão em todo o mundo. Nos diversos textos em que abordou a questão urbana, Munford visou sobretudo compreender e enfrentar as questões que a nova escala urbana metropolitana estava imprimindo a todos os aspectos da vida material. Enfatizou sobretudo as questões relativas à acomodação da população operária no interior das metrópoles cujo crescimento populacional tornou-se exponencial; a permanente expansão do território urbanizado; a congestão e seus corolários, isto é, a escassez de água, de transporte e de terra urbana. Antecipou de forma surpreendente as questões que as novas escalas infligiriam às metrópoles, tais como, apenas para citar um exemplo bem contemporâneo, a coleta, destinação e eliminação do lixo urbano. 
Embora suas conclusões acompanhem a tradição instaurada no século XIX, ou seja, transformar a metrópole num diabólico organismo de desorganização social e moral, sua abordagem produziu antecipações iluminadoras sobre a natureza do desenvolvimento metropolitano. Entretanto, a inexorabilidade imputada por ele ao processo de metropolização rumo à catástrofe final, retirou de sua brilhante descrição dos problemas metropolitanos a força analítica. É com perfeito controle de seu método de análise que Lewis Munford traçou um funesto quadro final que ele mesmo denominou "uma visão do inferno". ${ }^{3}$ A necrópole, último estágio da metrópole moderna, era, de acordo com sua leitura, a exacerbação e o desfecho lógico dos formidáveis aspectos negativos detectados desde o início do processo.

A abordagem culturalista de Munford forneceu, de maneira surpreendente, um quadro preciso das características complexas do desenvolvimento metropolitano sem no entanto mostrar-se suficiente para alcançar a lógica do processo que conduzia ao "estágio final do processo metropolitano", ou ainda, "ao destino da funesta megalópolis". Sua análise perde a força justamente quando seus argumentos tornam-se insuficientes, ou apenas inadequados, para abordar o papel ativo da metrópole na realização da metrópole do capitalismo industrial. Ao conduzir a análise para uma interpretação da metrópole como reflexo do desenvolvimento econômico da sociedade que a produz, ele deixou de considerar o papel da metrópole como agente desse desenvolvimento, transformando-a em vítima e eximindo de qualquer participação ativa no universo sombrio que descreve. De acordo com esse modelo de interpretação, o espaço físico metropolitano perde sua relação dinâmica com a sociedade, passando apenas a refleti-la. ${ }^{4}$ A metrópole assume o papel de "receptáculo passivo" no qual atuam as forças da sociedade determinando os padrões e as configurações de ocupação do espaço e do território. A metrópole/necrópole, tão bem caracterizada, perde sentido ao converter-se num organismo urbano resultante.

\section{O SENTIDO DA METRÓPOLE}

A rejeição de análises causais para compreender e descrever o percurso metropolitano é essencial para que se possa alcançar as peculiaridades de sua constituição, inflexões de seu trajeto e, até mesmo, as rupturas de seu desenvolvimento. Um desdobramento lógico da premissa que sustenta a metrópole ser expressão e não reflexo do modo de produção, leva a assumir a metrópole antes como um poderoso agente das transformações no interior do próprio sistema capitalista. E indo um pouco mais longe, é correto afirmar que sua organização física responde a exigências de todo tipo: econômicas, funcionais, simbólicas, estratégicas e outras, todas elas impostas pelo sistema produtivo que, desde a emergência da metrópole moderna, não abandonou seu incessante "impulso renovador". A expressão "impulso renovador" assinala aqui uma permanente imposição, interna ao próprio sistema produtivo, de introduzir formas e até mesmo funções comprometidas com uma "modernização acessória", isto é, destituída de valor social. Nesse processo o novo e a novidade governam as sociedades e portanto as cidades e metrópoles, substituindo de forma inadequada as estruturas urbanas tradicionais.

A observação do desenvolvimento urbano das metrópoles, sobretudo nos séculos XIX e XX, atesta seu indiscutível papel na consolidação do modo de produção industrial dos países onde se localizam. A partir de modelos e princípios urbanísticos muitas vezes distintos na aparência, mas bastante semelhantes na essência, o espaço de vida da sociedade industrial, localizado na metrópole moderna, apresentou variações de padrões urbanísticos ditados pela intensidade e pelo teor dos "impulsos renovadores". A disseminação desses modelos, como sempre ocorre com a difusão de valores econômicos e culturais, produziu resultados muito distintos fora de seus contextos originais. Assim, a metrópole européia, a americana, a latino-americana e as asiáticas criaram padrões de organização material, de formas de crescimento, de vida cultural urbana, de imagem urbana, de relações com a natureza, que exprimiram simultaneamente a lógica do sistema produtivo e a singularidade de seus contextos históricos.

Essas observações me permitem introduzir o clássico ensaio de Massimo Cacciari "Metropolis", 5 que oferece um excelente ponto de partida para a compreensão do desenvolvimento metropolitano. Para Cacciari "é no povoado que se inicia concretamente o destino da metrópole". Não se trata, é claro, de um determinismo histórico, mas apenas de uma interpretação do desenvolvimento metropolitano que aponta para o caráter progressivo e cumulativo do processo de metropolização. A aparentemente simples afirmação de Massimo Cacciari assinala um traço inerente à formação e ao desenvolvimento da metrópole, isto é, o seu caráter de espaço que se impõe, cuja trajetória é governada pelo seu permanente "impulso renovador" rumo a novos patamares. Há nessa interpretação do per- 
curso metropolitano uma implícita visão de "processos positivos", ou seja, de situações propiciadoras de um desenvolvimento intenso e rápido. A história das cidades e das metrópoles está repleta de exemplos de povoados que num espaço de tempo extremamente curto ganharam dimensão e função metropolitana.

Do ponto de vista de sua organização interna, a metrópole moderna instalou-se a partir da explosão sucessiva dos estágios urbanos precedentes, o povoado e depois a cidade, num ciclo que traduz a contínua necessidade de ser eficiente, de exercer de forma plena as suas funções de "lugar de centralização" de forças econômicas, de relações sociais, de manifestações artísticas e de inovação técnica. Essa natureza "inegociável" e muitas vezes violenta do desenvolvimento metropolitano se exprime de forma clara na sua dimensão material. Em função dessas características, tudo aquilo que "ganha corpo" na vida metropolitana exprime as relações estabelecidas em todas as suas esferas de vida social e produtiva, convertendo-se em expressão e não em reflexo dessas relações.

\section{A TRANSIÇÃO DA METRÓPOLE MODERNA PARA A METRÓPOLE CONTEMPORÂNEA}

A metrópole industrial abrigou, desde a sua consolidação no século XIX, as atividades da sociedade designadas como modernas. A concomitância entre o processo de metropolização e a renovação do modo de produção industrial a converteram no locus da sociedade industrial. A vida metropolitana foi, portanto, essencialmente moderna em todos os seus aspectos, desde sua origem. Nela organizou-se a sociedade de classes, emergiram a multidão e a massa, desenvolveu-se uma nova forma de cosmopolitismo e nasceu o indivíduo moderno. No âmbito da vida material, a metrópole ofereceu nesse estágio de desenvolvimento as condições territoriais indispensáveis para a instalação da grande indústria, para a organização do mercado consumidor e para o alojamento da classe trabalhadora. Assimilou e potencializou as inovações introduzidas pela Revolução Industrial participando de forma intensa da "revolução ininterrupta da produção". Um dos traços fundamentais, na esfera da vida política, foram as relações sociais conflitivas que se estabeleceram entre seus principais protagonistas, o proletariado e a burguesia urbano-industrial. No âmbito da vida espiritual e individual prevaleceram alguns traços muito marcantes do indivíduo moderno, tais como a ambigüidade e a angústia, que tornaram-se as principais características psi- cológicas do indivíduo que, seduzido pelas variadas formas de modernização da vida cotidiana, reconhecia as suas limitações e seus conflitos. Marshall Berman traduz com precisão o impacto dramático da metrópole sobre o indivíduo mostrando que a manifestação das divisões de classe na metrópole moderna implicou divisões interiores no indivíduo (Berman, 1986:149).

O "impulso renovador" se tornou a essência da própria dinâmica metropolitana. Converteu-se numa dimensão observável e analisável na medida em que se materializou no padrão de modernização imposto pela pressão de um crescimento sem trégua exigido pelo capitalismo industrial. Esse processo fez da metrópole moderna o fenômeno que sintetizou de forma mais completa o ideário da sociedade da Revolução Industrial. E é esse mesmo motor que conduziu o organismo metropolitano a prosseguir num processo ininterrupto de transformações, alcançando no final do século XX uma nova fase de seu percurso. A materialização de novos padrões de modernização oferece hoje uma face nova para a metrópole.

As metrópoles de todo o mundo, independentemente de sua localização geográfica global, de seu nível de desenvolvimento econômico e social, localizadas em países desenvolvidos, subdesenvolvidos ou em desenvolvimento, não cabem mais nas caracterizações utilizadas até os anos 70 para defini-las. A experiência pessoal, a observação científica e artística, os dados e as análises confirmam a gradual dissolução dos traços territoriais, funcionais e espaciais da metrópole moderna. Apesar de se encontrarem hoje em momentos distintos de adaptação ao novo perfil, pois algumas ainda estão abrindo seu caminho para uma nova etapa, para grande parte das metrópoles já não se pode utilizar o qualificativo que as designou até aqui: modernas.

O território e o espaço, onde está em andamento a transição de um modo de produção mecânico para um modo de produção tecnológico, vêm sendo designados como metrópole contemporânea. A sua definição, ou a descrição de seu conteúdo e forma passa obrigatoriamente pela compreensão de seu papel na reestruturação do próprio processo produtivo e econômico designado como pós-industrial (Castells, 1999:32; 202; 236; 238).

Uma vez que a tecnologia informacional, marco transformador do modo de produção e da nova economia mundializada, está no centro da revolução em curso, devemos considerar que o processo de reestruturação do território metropolitano vem participando ativamente das mudanças instauradas no padrão tecnológico. Veremos mais 
adiante como os projetos de reestruturação metropolitana estão criando novos atributos em todas as dimensões metropolitanas.

Essas considerações oferecem boa perspectiva para uma abordagem do atual processo de transição metropolitano. A partir das evidências oferecidas pela própria transição, são propostas algumas questões básicas como, por exemplo, quais foram as limitações observadas na metrópole moderna perante as exigências do atual marco tecnológico informacional e do próprio capitalismo globalizado para que um novo paradigma metropolitano tenha se imposto? Essa, acredita-se, seja a questão de fundo do processo de transição que está substituindo a "metrópole moderna" e suas insuficiências pela "metrópole contemporânea" com suas potencialidades. Prosseguindo com outras questões que se desdobram desta, é importante saber ainda o que distingue o velho modelo em processo de superação daquele novo que se instala. E mais, quais são os novos atributos, ou que características podem ser efetivamente classificadas como "novas"; há continuidades ou apenas descontinuidades no estágio anterior? E, para finalizar, uma questão sobre as funções do novo modelo metropolitano: é preciso conhecer a força e as atribuições da metrópole contemporânea, isto é, verificar se é correto falar em "protagonismo metropolitano".

Para enfrentar essas perguntas é preciso ter presente que qualquer abordagem da metrópole contemporânea deve levar em conta que não se está diante de um objeto plenamente configurado. Pelo contrário, o caráter provisional, transitivo do território e dos espaços metropolitanos dificulta a tarefa porque se observam simultaneamente características já detectadas na metrópole moderna porém alteradas e, muitas vezes, encobertas por novas relações com o padrão pós-industrial. Se por um lado temos uma efetiva transformação em andamento, por outro ainda é possível reconhecer a presença de uma considerável proporção de elementos permanentes vindos da etapa anterior. É nesses elementos ditos de continuidade que repousa, em inúmeros casos, o caráter distintivo das metrópoles espalhadas em todos os continentes, vivendo graus muito diferentes de desenvolvimento. Aliás, essa é uma questão que afeta de maneira mais clara as metrópoles pobres onde os graus de precariedade urbana relacionados ao período da industrialização intensa são mais profundos.

Dito de outra forma: os problemas urbanos acumulados na metrópole moderna, sobretudo no período de instalação da grande indústria, passam a coexistir com as exigências e as pressões da "nova etapa" metropolitana, criando um cenário urbano no qual o descompasso entre a organização que está sendo superada (a metrópole moder$n a$ do estágio industrial) e aquela que se instala (a metrópole contemporânea do estágio pós-industrial) é extremamente acentuado. Revelar e analisar as diversas faces desse quadro urbano, resultantes do conflito que se instala entre aspectos deficientes e modernizados, é fundamental para entendê-las e os conteúdos do processo de transição.

\section{NOVAS FUNÇÕES PARA A INFRA-ESTRUTURA METROPOLITANA}

Assim como ocorreu na constituição da metrópole moderna, a constante remoção dos limites físicos é ainda um atributo fundamental na reestruturação da metrópole contemporânea. A análise da expansão territorial e da distribuição das atividades da sociedade no interior de espaços constantemente ampliados é, por analogia à etapa anterior, um recurso muito utilizado para acompanhar as suas transformações impulsionadas pela substituição do modo de desenvolvimento industrial pelo informacional.

Está bastante claro, entretanto, que, sem uma reflexão das especificidades da atual organização metropolitana, nada se acrescentará à compreensão da nova ordem urbana e, cada vez mais, que as abordagens comprometidas com os padrões de organização territorial da metrópole moderna, hoje em claro processo de superação, conduziram a conclusões equivocadas. Até mesmo o uso indiscriminado dos termos megacidade e cidade mundial, que não traduzem a natureza da metrópole contemporânea, acabou por confundir as observações e análises.

A advertência feita por Massimo Cacciari de que a metrópole contemporânea não deveria ser confundida com nenhuma categoria particular de grande cidade, nem comercial nem tampouco industrial, começou finalmente a fazer sentido, diante das evidências e do porte das transformações introduzidas pelo processo de substituição física e funcional. O novo organismo metropolitano só veio a ser perceptível quando se passou a aceitar teórica e pragmaticamente que a essência da metrópole contemporânea reside no fato de ser um sistema, ou "um tipo urbano pluriarticulado, um serviço global e dirigido ao desenvolvimento do grande capital contemporâneo". A força da análise de Cacciari repousa na argumentação que os processos de "metropolitação" e de estruturação da metrópole estão voltados para o desenvolvimento do grande capital contemporâneo. Assim como a metrópole moder- 
na, a metrópole contemporânea é ao mesmo tempo uma forma de organização da força de trabalho qualificada, um equipamento científico do desenvolvimento econômico, uma estrutura econômico-financeira, um mercado, um centro global de poder político e um centro de irradiação de conhecimento e cultura.

É fundamental não perder de vista, sob pena de produzir outros equívocos, que está em jogo não apenas a simples substituição da atividade industrial pela de serviços, mas algo bem mais complexo, ou seja, a ampliação de suas atribuições no interior do novo estágio em todos os níveis e aspectos da etapa produtiva denominada pós-industrial. É uma banalização despropositada desse processo de transição metropolitana avaliar e comparar a permanência ou substituição de atividades industriais, pois cada uma das etapas do desenvolvimento socioeconômico gerou nas cidades e metrópoles, em graus variados, a permanência de atividades centrais da etapa que se encerrava.

Assim, as funções mercantilistas permaneceram vivas e cruciais no interior da metrópole industrial. Autores que já estão analisando o processo desde a década de 70 , (Touraine, 1969; Castells, 1995), têm demonstrado com abundância de dados e inovação teórica que a atual transição não é apenas uma simples substituição de produtos por serviços, mas a emergência do modelo tecnológico informacional que condiciona a produção, a distribuição, o consumo e a administração.

Essa substituição gera uma importante transformação no padrão urbano e introduz um novo conceito, decisivo para a compreensão da metrópole contemporânea: "espaço dos fluxos". Já muito presente na literatura especializada, o conceito de "espaço dos fluxos" incide num atributo primordial da metrópole: a contigüidade física do território (Castells, 1999:435).

É historicamente reconhecido que a origem das metrópoles modernas foi em grande medida um movimento de agregação, e a palavra conurbação traduz do ponto de vista semântico a ação de reunir em um todo diversos núcleos e cidades pela unificação das suas malhas urbanas, respeitando uma hierarquia funcional. Em suma, a metrópole é acima de tudo a expressão de um processo de articulação e não de desarticulação do território urbanizado. É esse $o$ atributo que a distingue das demais formas de organização territorial. Na metrópole moderna o crescimento ilimitado produziu um organismo expandido, extenso, multifacetado e setorizado, em que o traçado viário buscava reforçar a estrutura e fazer perante a dispersão, já na metrópole contemporânea a forma e a continuidade do tecido urbano deixam de ser metas para tornarem-se condicionantes. As duas palavras-chave utilizadas para descrever física e funcionalmente o novo organismo, desde os anos 70 quando o fenômeno se tornou patente, são fragmentação e dispersão. Ambas apontam a tendência do território a romper as continuidades urbanas tradicionais (fragmentação) e, como resposta, gerar núcleos de atividades difusos e insulados (dispersão).

Embora perceptíveis, são justamente esses dois conceitos que, à luz das experiências espaciais e territoriais em andamento, deverão sofrer uma reavaliação. Pois é patente, na reestruturação da metrópole contemporânea, de acordo com o padrão do "espaço dos fluxos", que tanto a contigüidade espacial quanto a continuidade territorial são hoje garantidas por meios que dispensam o suporte material e o territorial convencionais, isto é, o espaço urbano. Por definição o "espaço dos fluxos" garante a articulação entre trechos urbanos aparentemente descontínuos e desarticulados.

O estudo do desenvolvimento metropolitano, a definição de suas características físicas, a avaliação de seu desempenho e de sua materialidade, estão subordinados aos seus sistemas de organização físico-espaciais e às suas redes de funcionamento. Para observar com método as suas formas de crescimento, descrever a configuração gerada pela fragmentação física e pela dispersão funcional das atividades no território, é preciso definir os elementos que comandam a atual "dinâmica de organização" de seus sistemas e redes. Nesse sentido, é indispensável procurar caracterizar com muito cuidado as formas de apropriação do território e a nova disposição e organização dos espaços urbanos a partir da compreensão desses sistemas que nem sempre se oferecem à nossa percepção.

A "configuração organizadora", responsável pela unidade metropolitana, tão cara ao projeto urbano e modernista, ${ }^{6}$ converte-se agora numa aspiração obsoleta. A procura incessante da forma no interior da metrópole, sempre vista como importante informação e objetivo legítimo, perde função e sentido. O reconhecido mal-estar diante da ausência de uma forma urbana racional, da insistente presença da indesejável mancha de óleo, está sendo superado por "irracionalidades" que sequer se oferecem com clareza para o nosso exame mais cuidadoso.

A dinâmica que se instalou no território metropolitano contemporâneo está, aceleradamente, diluindo a forma urbana, tomada no seu sentido mais linear ou como configuração urbana in-extenso, para substituí-la por um imenso conjunto de espaços e objetos construídos que não re- 
velam as conexões espaciais e funcionais a que estão subordinados. O mesmo ocorre com a importante questão da escala metropolitana que não poderá mais ser vista apenas como superfície contínua. Dessa forma, além de difícil, é ilusório fixar qualquer um de seus arranjos momentâneos como expressão formal de sua organização. Para contornar essas dificuldades e buscar uma aproximação da nova ordem urbana e para que o grau de diluição das atividades no território - Habermas (1987) fala em abstração - e no espaço urbano não permaneça como obstáculo para a nossa percepção, pode-se tentar lançar mão de um recurso metodológico baseado na conjugação de aspectos da vida metropolitana: considerar que a organização - funcional e formal - da metrópole contemporânea é definida simultaneamente pelos sistemas de infraestrutura metropolitanos, pelos pólos que dão suporte às atividades da sociedade no território e por seus deslocamentos diários no interior do seu território e de seus espaços.

Mantendo uma distância crítica das análises que celebram o caos, assim como daquelas que o vêem como inevitável, alguns estudos começam a mergulhar na lógica interna, na auto-organização da metrópole contemporânea. Abandonando as formas voluntaristas de "agir sobre o território", seja por normas ou por projetos de intervenção adaptadora, uma nova postura diante da metrópole contemporânea tem se mostrado mais eficaz: o discernimento de sua lógica de organização e funcionamento. Partindo do princípio que a organização territorial metropolitana sustenta-se na distribuição dos seus sistemas de infra-estrutura, pode-se deduzir que existem pontos precisos no território metropolitano nos quais ecoam, de forma mais evidente, as duas escalas urbanas: a metropolitana e a local. O reconhecimento desses "pólos de convergência", pelas características de sua organização e potencialidade, são hoje o principal foco do pensamento e da ação urbanística.

A estruturação da cidade metropolitana depende portanto de grandes projetos urbanos. E o "valor estratégico" desses projetos está por sua vez subordinado à sua capacidade de promover transformações do meio urbano regional, aumentando sua atratividade e expandindo sua área de influência. Nesse sentido, esses projetos diferem substancialmente das antigas ações de "melhoramentos urbanos" que, muitas vezes, respondem apenas às demandas pontuais e específicas. Hoje, para que se possa avançar, é fundamental esclarecer as questões possíveis por enquanto de serem definidas como funcionais. A análise dos planos e projetos que recebem tratamento prioritário para promover desenvolvimento urbano ou modernização também é opção que traduz as relações que estão se estabelecendo no interior do processo de instalação de um novo modelo de metrópole.

Independentemente da força institucional da entidade metropolitana, o projeto desenvolvido em escala metropolitana é sempre impulsionado e sustentado por questões abrangentes, que só encontrarão respostas efetivas nessa escala, tanto para estabelecer as políticas públicas como o projeto urbano: os recursos naturais, as grandes infra-estruturas sistêmicas, a definição de funções municipais complementares e a interação dos vários sistemas distribuídos no território. Fica portanto evidente que o caráter sistêmico de questões como mobilidade e transporte, abastecimento de água, macrodrenagem, destinação de resíduos sólidos, qualidade do ar e inúmeros outros, menos óbvios, só encontrará respostas técnica e política consistentes quando tratado na escala correta.

Nas atuais circunstâncias parece ocioso procurar o princípio de agregação do território metropolitano, pois essa atitude guarda algo da tradicional idéia de que existe um "princípio agregador" no interior das metrópoles. Mas tudo indica que a fragmentação e a dispersão do espaço e do território são dois fenômenos em processo de revisão. Hoje, as mais atentas análises do território metropolitano já assinalam "as pontas do iceberg", ou seja, as evidências de incipientes elementos de aglutinação. A hipótese de que as grandes infra-estruturas urbanas ganharam a prerrogativa de funcionar como elemento "agregador" do território metropolitano torna-se evidente. Deixando de ser apenas "redes abstratas que enfeixam conexões funcionais", a infra-estrutura urbana contemporânea cumpre a função básica de organizar os sistemas e subsistemas urbanos, estruturando a metrópole, garantindo as continuidades ameaçadas pela fragmentação e organizando os fluxos que evitam a dispersão funcional.

\section{NOTAS}

E-mail da autora: reginameyer@that.com.br

1. Uma extensa bibliografia atesta a fecundidade destas abordagens. Marshall Berman em Tudo que é sólido desmancha no ar (1986) produz uma excelente revisão bibliográfica do tema.

2. No texto de Lewis Munford A cidade na história, publicado em 1961 nos Estados Unidos, a história tem um papel fundamental no processo de constituição e desenvolvimento das cidades. Munford foi, ao lado de Patrick Geddes, um pensador historicista e culturalista.

3. Esta expressão está presente no último capítulo de $A$ cidade na história (Munford, 1998). 
4. Ver Castells (1999), capítulo 6.

5. O texto de Massimo Cacciari "Metropolis" está no livro De la vanguardia a la metropoli (crítica radical da arquitetura). Os dois outros autores são Manfredo Tafuri e Francesco dal Co. Os ensaios que compõem o livro são parte de um trabalho coletivo de orientação marxista desenvolvido pelos autores no Instituto de História da Arquitetura do Instituto Universitário de Veneza, a partir de 1968.

6. Embora presente em diversos textos de arquitetos modernistas, a idéia da forma urbana como expressão de equilíbrio urbano ganhou nova leitura a partir da abordagem feita por Manfredo Tafuri em Projeto e utopia (1985:35).

\section{REFERÊNCIAS BIBLIOGRÁFICAS}

BERMAN, M. Tudo que é sólido desmancha no ar. São Paulo, Cia das Letras, 1986
CACCIARI, M. "Metropolis". In: De la vanguardia a la metropoli. Barcelona, Gustavo Gilli, 1972.

CASTELLS, M. The informational city. Oxford-UK, Blackwell, 1995.

$$
\text { . A sociedade em rede. São Paulo, Paz e Terra, } 1999 .
$$

HABERMAS, J. “Arquitetura moderna e pós-moderna”. Novos Estudos. São Paulo, Cebrap, 1987.

MEYER, R.M.P : LEME, M.C.; GROSTEIN, M.D e BIDERMAN, C. São Paulo metrópole terciária. Entre a modernização pós-industrial e a herança social e territorial da industrialização. Relatório Final de pesquisa desenvolvida pela FAU-USP/Ipea/Cebrap. São Paulo, 1998.

MICHELL, W.J. City of bits. Cambridge-Massachusetts, MIT. Press, 1996.

MUNFORD, L. A cidade na história. São Paulo, Martins Fontes, 1998.

TAFURI, M. Projeto e utopia. Lisboa, Editorial Presença, 1985.

TOURAINE, A. La société post-industrielle. Paris, Denoel, 1969.

SECCHI, B. Prima lezione di urbanistica. Roma-Bari, Editori Laterza, 2000. 